\title{
A COBERTURA VERDE EM EDIFICAÇÕES
}

Igor Rafael Tadashi Watanabe, Sibila Corral De Arêa Leão Honda.

Universidade do Oeste Paulista - UNOESTE, Faculdade de Engenharias e Arquitetura e Urbanismo, Presidente Prudente, SP. E-mail: sibila.honda@sibila.arq.br

\section{RESUMO}

O processo de projeto de uma edificação deve incluir todos os aspectos almejados. O projeto estrutural precisa ser específico para cada edificação projetada. Cada aspecto que possa gerar peso sobre a estrutura deve ser criteriosamente observado. Atualmente, verifica-se forte tendência mundial à inclusão de vegetação na cobertura, independente de razões estéticas, de conforto da edificação ou ambientais. No entanto, a cobertura verde pode interferir no projeto estrutural, dependendo do tipo de sistema aplicado e da vegetação escolhida. Com isso, esta pesquisa objetivou analisar essas características, apoiando conhecimentos da área da engenharia civil. A metodologia teve como base uma investigação teórica sobre telhado verde e sua composição.

Palavras-chave: Cobertura, Construção civil, Telhado verde.

\section{THE GREEN COVER IN BUILDINGS}

\section{ABSTRACT}

The process of a building project must include all the desired aspects. The structural design must be specific to each designed building. Every aspect that can generate weight on the structure should be carefully observed. Currently, there is global trend towards the inclusion of vegetation on the roof, regardless of aesthetic reasons, the comfort of the building or environmental. However, the green cover can interfere with the structural design, depending on the system applied and the chosen vegetation. Thus, the objective of this research was to analyze these characteristics, supporting knowledge of civil engineering area. The methodology was based on a theoretical research on green roof and its composition.

Key-words: Cover, Building, Green Roof. 


\section{INTRODUÇÃO}

Atualmente, a maior parcela da população mora nos centros urbanos, e verifica-se que construção de unidades residenciais e outros tipos de edificações podem ser identificados como elementos causadores ou estimuladores de impactos ambientais. Ao mesmo tempo, a construção das cidades também tem relação direta com a redução de vegetação local. No entanto, a existência de vegetação proporciona redução da temperatura do clima local, devido à absorção e consumo da energia solar, e devolução de umidade do ar por meio da evapotranspiração.

Ao contrário, edificações com utilização de utilização de vegetação na cobertura pode vir a reverter aspectos negativos da falta/carência de vegetação intra-urbana, mas precisa ser cuidadosamente projetada pois amplia fortemente o peso dessa edificação, cuidado que deve ser tomado durante a elaboração do projeto estrutural da mesma. Ou seja, é importante projetar a estrutura de forma que suporte o peso extra, principalmente a estrutura da cobertura, seja em laje de concreto ou estrutura de telhado, que suporte o peso que virá a ser instalado, assim como o peso da água de chuva nessa cobertura verde.

Dessa forma, essa pesquisa visa a identificar e analisar a cobertura verde em edificações. A metodologia seguida se apoia em levantamentos bibliográficos sobre o assunto, identificação de composição e espécies vegetais desse tipo de cobertura, características construtivas e de peso próprio.

\section{METODOLOGIA}

A metodologia utilizada na pesquisa foi qualitativa, baseada em levantamentos bibliográficos teóricos para compreender como pode ser estruturada a cobertura verde em edificações.

\section{ANÁLISES}

A partir de meados do século XX, podem ser identificadas discussões a respeito de preocupações com o meio ambiente natural, que tem como reflexo o ambiente construído, e inicia-se um conflito entre ser humano e a natureza (GOLDBLATT, 1996). França (2012) informa que no século XXI, após o início do processo de globalização, são percebidas as necessidades de preservar os recursos naturais ainda existentes assim como recuperar áreas impactadas pela ação do homem.

Segundo Ferreira e Moruzzi $(\mathrm{s} / \mathrm{d})$, o telhado verde foi concebido há muitos séculos; sendo que a tecnologia para sua implantação é identificada em diferentes regiões do mundo, como na Escandinávia antiga, onde eram utilizados telhados cobertos com terra e grama, visando ao isolamento térmico, devido ao frio; e sob essa camada eram colocadas cascas de árvores para suporte e impermeabilização, suportadas pelo madeiramento.

Há diversos benefícios de telhados verdes, entre eles, podem ser citados o conforto térmico interno da edificação, redução do clima local, redução e controle do escoamento das águas superficiais (FERREIRA e MORUZZI, s/d). França (2012) destaca como grande benefício do telhado verde a minimização do aquecimento global, devido à fotossíntese e evopotranspiração, realizando sequestro de carbono atmosférico, reduzindo a temperatura do ar localmente, alterando a pressão atmosférica, influenciando no clima urbano. Esse autor também ressalta o isolamento termoacústico resultante do telhado verde.

Nas cidades, as coberturas verdes vegetais têm relação com a poluição do ar, tornandose filtros, a manutenção da umidade local, além das características estéticas e ornamentais (GOMEZ, GAJA, REIG, 1998). Segundo Oliveira (2009), o planejamento urbano ambiental e a preocupação com a implantação de telhado verde, podem ser relacionadas à economia de 
energia, racionalidade de consumo, redução das emissões de poluentes e manutenção do ciclo hidrológico local.

Sobre a composição do telhado verde, inclui-se a laje (pavimento) de cobertura acima da estrutura, impermeabilização, camada que possibilite a drenagem da água sobre o telhado, camada de terra (substrato) onde a vegetação será plantada, e a própria vegetação. Em relação à laje, por exemplo, vários materiais podem ser utilizados como tal, entre eles: laje de concreto, tabuado de madeira, chapas de compensado estruturado, placas cimentícia, bambu, entre outros (SAVI, 2012).

Assim sendo, verifica-se necessário o adequado dimensionamento da construção do telhado verde, devido ao excesso de carga. Importante destacar também que é fundamental verificar como será estruturada a laje, a camada de drenagem, do substrato e o tipo de vegetação, pois podem causar alterações na carga.

A composição do telhado verde pode variar de acordo com sua necessidade, e a situação em que se encontra a estrutura da construção e do telhado. Basicamente é composto por camada impermeabilizante, camada drenante, camada filtrante, membrana de proteção contra raízes, solo, substrato e a vegetação (Figura 1).

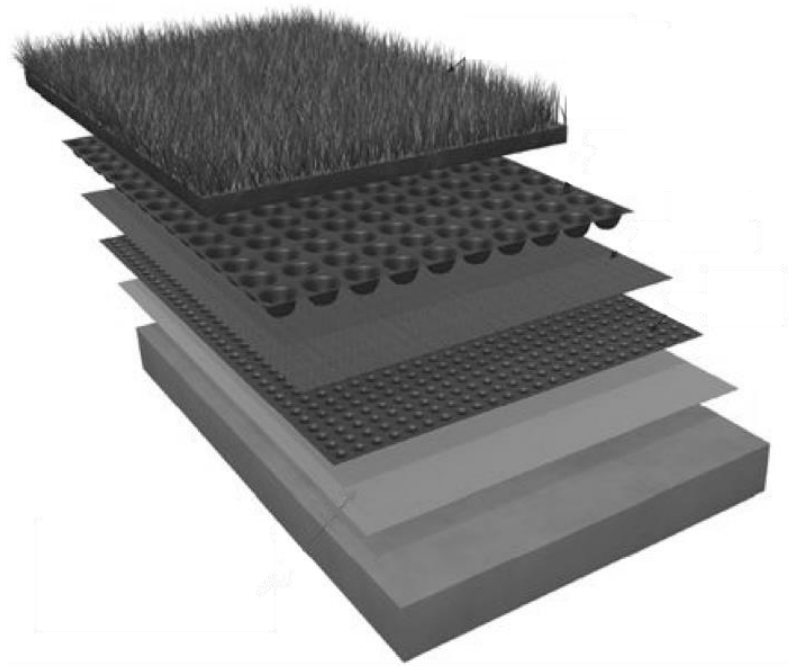

Figura 1. camadas do telhado verde (Fonte: http://infraestruturaurbana.pini.com.br, 2016)

A camada impermeabilizante tem função de conservar a laje ou telhado de infiltrações e umidade. Existem diversos tipos de materiais impermeabilizantes segundo Mello (2005, apud Denver, 2005), como: asfaltos de destilação direta, polímeros sintéticos, asfaltos oxidados, emulsões asfálticas, emulsões termosplasticas, mantas de asfalto e poliméricas sintéticas, entre muitos outros.

A camada drenante ajuda na absorção e no encaminhamento do excesso de água, podendo servir também como um filtro, utilizando britas, seixos, argilas expandidas. A camada filtrante auxilia na retenção de partículas. A membrana de proteção contra raízes impede que o crescimento das raízes danifique as demais camadas. O solo e o substrato são camadas onde será plantada a vegetação, assim como é por onde há transito de pessoas. A vegetação é a cobertura com gramíneas, forrações, arbustos e plantas de pequeno porte. A vegetação é um dos fatores que mais contribuem para o aumento do peso estrutural, isso por que dependendo do porte e da sua capacidade de armazenamento de água, obriga o planejamento estrutural mais especifico.

A necessidade do índice de inclinação em telhados planos esta diretamente ligada à conservação e a durabilidade, tanto da laje quanto da vegetação. A água quando acumulada pode dar inicio a infiltrações, transbordamentos que futuramente causará patologias na estrutura, o apodrecimento das raízes e o aparecimento de fungos, diz Silva (2011). Segundo 
Silva (2011), o jardim suspenso tem uma vasta variedade de índices de inclinação em que pode ser aplicado sendo o mínimo de $2 \%$, máximo de $35 \%$ sem travamento e de $75 \%$ com travamento e barreiras.

\section{DISCUSSÃO}

Existem três tipos básicos de sistemas de implantação e construção da cobertura verde, segundo Pereira (2007) e Silva (2011), sendo: aplicações continuas, com módulos préelaborados e aéreos. Que serão especificados a seguir.

Continuas - esta forma de aplicação é considerada a mais antiga, onde a camada do substrato é inserida diretamente sobre a base, que esta apropriadamente impermeabilizada e com as demais camadas protegendo-a. Neste sistema as camadas podem variar de acordo com o clima da região e a base utilizada. Exigindo a necessidade de camadas contra a condensação do vapor d'água em lugares frios.

Módulos pré-elaborados - é uma cobertura que faz a utilização de módulos fabricados para encaixe e compostos por uma bandeja rígida, substrato e vegetação, tendo como principal característica a rápida e fácil aplicação. Comercializada geralmente por empresas especializadas. Segundo Silva esse sistema pode ser subdivido em sistema modular, alveolar e laminar.

Modular - são módulos compostos geralmente de materiais biodegradáveis, como por exemplo, módulos de fibras de coco, e podem ser utilizadas em coberturas planas e inclinadas. Seu peso saturado é $80 \mathrm{~kg} / \mathrm{m}^{2}$.

Alveolar - Utiliza módulos compostos por resíduos de EVA (etil vinil acetato) moídos e aglutinados com cimento, preenchidos com substrato nutritivo e funcionam como um xaxim artificial. Seu peso saturado chega a ser entre 60 e $80 \mathrm{~kg} / \mathrm{m}^{2}$, variando de acordo com a vegetação escolhida, explica Silva (2011). Na estrutura alveolar diferentemente da laminar possui o acréscimo de três membranas: a antirraizes de polietileno de alta densidade, alveolar que retém a água e por baixo forma canais drenantes e a filtrante que retém os nutrientes.

Laminar - Tem como característica principal o armazenamento de água abaixo dos módulos, podendo ser reaproveitada para fins não potáveis. Silva apud Guimarães (2010), diz que esse sistema se caracteriza pela utilização de uma lamina d'água sob um piso elevado feito de módulos de sustentação, garantindo suprimento de água de ate $40 \mathrm{~L} / \mathrm{m}^{2}$ e só devem se usados em telhados completamente planos. Seu peso saturado é $120 \mathrm{~kg} / \mathrm{m}^{2}$, podendo variar de acordo com a vegetação, explica Silva (2011).

Cobertura Aérea - é um sistema que se caracteriza pela separação da vegetação e a cobertura, sua vantagem é a não sobrecarga estrutural, mas acaba perdendo no quesito isolamento do interior, pois a vegetação esta diretamente ligada a uma estrutura separada ao da cobertura, trabalhando de forma independente. $E$ ao invés da utilização de solo e substrato é utilizada uma tela, segundo Silva.

Segundo Savi (2012), os grandes centros urbanos sofrem com a ocupação desordenada e a falta de planejamento urbano, que acarreta no aumento urbano e uma grande parcela de solo impermeabilizado. Causando uma sobrecarga nos sistemas de drenagem, acarretando as enchentes. $\mathrm{E}$ o telhado verde pode ser um aliado para aliviar o sistema de drenagem urbana.

Savi (2012) também elaborou análise comparativa entre três sistemas distintos de cobertura (laje impermeabilizada, telha cerâmica, telhado verde), tendo concluído que se pode ter uma redução de $70 \%$ da água escoada para as galerias pluviais com um telhado extensivo de $5 \mathrm{~cm}$ de substrato, mostrando também a sua real contribuição na evapostranspiração e na redução do fluxo de água escoada.

A camada de drenagem, segundo Savi (2012), tem duas funções: sendo a primeira, a de encaminhar a água para que o solo não fique completamente saturado, e a outra função é a de 
armazenar água para a vegetação. A utilização mais eficiente de sistema de drenagem são os materiais porosos, como argila expandida, ou a utilização de sistemas modulares que retêm a água. É necessária a colocação de uma manta retentora de substrato sobre a camada de drenagem para que não haja a penetração da terra e crie um mau desempenho da drenagem da água.

\section{CONCLUSÃO}

A partir dessa pesquisa, foi possível compreender como a cobertura com vegetação pode vir a influenciar no projeto da estrutura das edificações. Atualmente, muitas cidades têm aprovado leis que estimulam ou obrigam a implantação de cobertura verde. Assim sendo, esta pesquisa auxiliará fortemente nessa área de conhecimento.

\section{REFERÊNCIAS}

FERREIRA, C.A.; MORUZZI, R.B. Considerações sobre a aplicação do telhado verde para captação de água de chuva em sistemas de aproveitamento para fins não potáveis. S/D. Disponível em: www.pliniotomaz.com.br/downloads/10moruzzi.pdf. Acesso em: 12.mar.2015.

FRANÇA, L.C.J. O uso do telhado verde como alternativa sustentável aos centros urbanos: opção viável para a sociedade moderna do século XXI. Revista Húmus. v.2, n.4. pp 105-113. 2012. Disponível

em: www.periodicos.ufma.br/index.php/revistahumus/article/view/1612/1274. Acesso em 13.mar.2015.

GOLDBLATT, D. Teoria Social do Ambiente. Lisboa: Instituto Piaget. 1996.

GOMEZ, F.; GAJA, E.; REIG, A. Vegetation and climates changes in the city. Ecological Engineering. v.10, n.4. pp.355-360. 1998. Disponível em: http://www.sciencedirect.com/science/article/pii/S0925857498000020. Acesso em: 10.mar.2015.

IGRA - http://www.igra-world.com/types of green roofs/index.php MELLO, Luciano Soares Lucas. Impermeabilização - Materiais, Procedimentos e desempenho. 2005.

OLIVEIRA, E.W.N. Telhados verdes para habitações de interesse social: retenção das águas pluviais e conforto térmico. Rio de Janeiro: UERJ. 2009. (Dissertação de Mestrado). Disponível em:

http://www.peamb.eng.ueri.br/trabalhosconclusao/2009/EricWatsonNettodeOliveiraPEAMB 2 009.pdf. Acesso em: 06.mar.2015.

PEREIRA. Manoela de Freitas. Teto verde: o uso de coberturas vegetais em edificações. Rio de Janeiro. $2007.2 \quad$ http://www.pucrio.br/Pibic/relatorio resumo2007/relatorios/art/art manoela de freitas ferreira.pdf

SILVA, Neusiane da Costa. Telhado verde: sistema construtivo de maior eficiência e menor impacto ambiental. 2011.

SAVI, A.C. Telhados verdes: análise comparativa de custo com sistemas tradicionais de cobertura. Curitiba: Universidade Tecnológica Federal do Paraná. 2012. (Monografia de 
Especialização).

Disponível

em:

file://C:/Users/usuarios/Downloads/CT CECONS II 2012 01\%20(2).pdf. $\quad$ Acesso

em: 05.mar.2015. 